\title{
FENOMENOLOGIA E PSICOLOGIA DA CRIANÇA:
}

\section{MERLEAU-PONTY E WINNICOTT}

\author{
Phenomenology and Child Psychology: Merleau-Ponty and Winnicott
}

Litiara Kohl Dors*

Resumo: O artigo visa explorar alguns pontos de convergência entre as posições do fenomenólogo francês Maurice Merleau-Ponty e o pediatra e psicanalista inglês Donald Winnicott em relação ao tema da intersubjetividade e da criança. Ao propor as bases para uma ontologia da "carne", Merleau-Ponty procura mostrar que não há limites definidos entre interior ou exterior. Há um campo perceptivo de intersecção, isto é, uma zona de reversibilidade e permeabilidade. A Carne exprime, portanto, o meio formador do sujeito e do objeto. Ora, esse nível de experiência da Carne como um Ser indivisível parece bem ser o pano de fundo pelo qual Winnicott aborda o espaço transicional como uma zona intercambiável, sem fronteiras rígidas entre o eu e o não-eu. Nessa perspectiva winnicottiana, o início da vida deixa de ser uma relação dual entre mãe e bebê. Ambos interagem num só "espaço", num só meio recíproco de relações carnais, desconstruindo, portanto, qualquer posição solipsista.

Palavras-chave: Merleau-Ponty. Fenomenologia. Winnicott. Psicanálise. Criança.

\begin{abstract}
This article's purpose is to explore some points of convergence between the positions of the French phenomenologist Maurice Merleau-Ponty and the English pediatrician and psychoanalyst Donald Winnicott on the topic of the inter-subjectivity and the child. In proposing the basis for ontology of "flesh", Merleau-Ponty seeks to show that there are no limits defined between the inside or outside. There is a perceptual field of intersection, that is, an area of reversibility and permeability. The Flesh thus expresses the means forming the subject and the object. Now, this level of experience of the Flesh as an indivisible Being seems to be the background by which Winnicott addresses the transitional space as an interchangeable area without rigid boundaries between the self and non-self. In this perspective of Winnicott, the beginning of life ceases to be a dual relationship between mother and baby. Boths interact in one "space", a single reciprocal means of carnal relations, deconstructing, therefore any solipsistic position.
\end{abstract}

Keywords: Merleau-Ponty. Phenomenology. Winnicott. Psychoanalysis. Child.

\footnotetext{
* Mestre em Filosofia pela Universidade Estadual do Oeste do Paraná: E-mail: litiara@ hotmail.com
}

\begin{tabular}{|c|c|l|l|l|l|}
\hline intuitio & $\begin{array}{c}\text { ISSN } \\
1983-4012\end{array}$ & Porto Alegre & Vol.9- $\mathrm{N}^{\mathrm{o} .1}$ & $\begin{array}{l}\text { Julho } \\
2016\end{array}$ & p.82-97 \\
\hline
\end{tabular}


Merleau-Ponty buscou desenvolver, no interior de sua filosofia, as bases para uma nova ontologia que, particularmente em seus escritos tardios, como veremos logo mais, institui o estatuto da emblemática noção de "carne". Na contramão do pensamento cartesiano, tal projeto retoma e aprofunda a intuição fenomenológica de um retorno às próprias coisas; um retorno que se radica ao nível da sensibilidade. Merleau-Ponty estabelece, como mote desse projeto, a tarefa de uma "reabilitação ontológica do sensível"; o sensível, aqui, compreendido não como um fato empírico, mas como um domínio radicalmente originário, anterior ao pensamento. É, portanto, nesse nível ontológico que, aos seus olhos, se rompem as barreiras entre objetividade e subjetividade, corpo e consciência, eu e outrem, exterior e interior.

É digno também de nota que o filósofo retoma a fenomenologia husserliana retraçando nela novos contornos, sem deixar, ainda, de abrir caminho a uma ontologia que leve em conta, por sua vez, uma nova teoria da intersubjetividade. É nesse ponto, mais precisamente, que se pode medir a pertinência de uma profícua aproximação com Winnicott, o qual, muito embora se tenha distanciado de seus predecessores (Freud, Lacan e Melanie Klein), se projeta, de maneira original, no horizonte da tradição psicanalítica. Winnicott figura, então, como um observador clínico das relações entre os bebês e suas mães, retratando que não há, no início da vida, diferenciação entre o eu e o não-eu. Ora, isso significa que a criança, logo após o nascimento, não apresenta a compreensão de estar separada do mundo e dos seus objetos. Há, aí, um sentimento de união com o mundo e com os outros indivíduos, em especial com a figura da mãe. Ao mesmo tempo, há um sentimento de onipotência, por parte do bebê, no sentido de que ele deve ser motivado por um espírito mais criativo. Assegurar esse sentimento de autonomia é já uma das funções primordiais da figura materna no início do desenvolvimento.

Tratamos, pois, aqui, de autores que, embora contemporâneos e tendo interlocutores em comum (como Lacan e Melanie Klein), muito provavelmente não chegaram manter qualquer contato entre si. As consultas aos textos de ambos também parecem evidenciar ou corroborar tal impressão. O fato é que, conforme bem nota o psicanalista Jean-Bertrand Pontalis, numa nota de rodapé de seu texto Presença, entre os Signos, Ausêncial, o pensamento merleau-pontyano parece se situar mais próximo, do ponto de vista teórico, das posições de Winnicott do que, propriamente de Melanie Klein, com quem, aliás, mais diretamente travou um acurado debate. Para Pontalis, um dos conceitos que justificaria tal proximidade entre Merleau-Ponty e Winnicott é o fenômeno da transicionalidade. Quer dizer: ambos os pensadores procuram explorar a existência de uma área de transição entre a realidade e a fantasia, entre o mundo interno e externo ao sujeito, entre o "dentro" e o "fora". Tanto para o psicanalista quanto para o filósofo,

\footnotetext{
${ }^{1}$ Cf. PONTALIS, J.-B. Entre o sonho e a dor. Tradução de Cláudia Berliner. Aparecida, SP: Ideias e Letras, 2005.
}

\begin{tabular}{|c|c|l|l|l|l|}
\hline intuitio & $\begin{array}{c}\text { ISSN } \\
1983-4012\end{array}$ & Porto Alegre & Vol.9- $\mathrm{N}^{\mathrm{o}} .1$ & $\begin{array}{l}\text { Julho } \\
2016\end{array}$ & p.82-97 \\
\hline
\end{tabular}


os conceitos reportados acima se apresentam como eixos fundamentais para a compreensão das relações construídas pelos indivíduos com os objetos da cultura e com os outros sujeitos. ${ }^{2}$

Winnicott debateu amplamente o conceito de transicionalidade por meio daquilo que ele caracteriza conceitualmente de fenômenos e objetos transicionais e que ocorrem aproximadamente durante o primeiro ano de vida do indivíduo. Segundo explica o psicanalista, sua hipótese inicial é a de que, logo ao nascerem, os bebês tendem a usar o punho, os dedos e os polegares para estimulação e satisfação dos instintos da zona erógena oral e, após algum tempo, passam a gostar de brincar com alguns objetos como, por exemplo, uma ponta de cobertor ou um bicho de pelúcia, apegando-se mais intimamente. Ora, é em virtude dos acontecimentos no intervalo de tempo transcorrido entre estes dois conjuntos de fenômenos que o autor reconhece a verdadeira importância do estudo da transicionalidade. Nessa medida, como ele mesmo escreve, "[...] aquilo a que me refiro nesta parte de meu trabalho não é o pano nem o ursinho que o bebê usa; não tanto o objeto usado quanto o uso do objeto". 3

O autor, acima de tudo, não está aqui interessado no objeto específico ou concreto, mas, sim, na “[...] primeira possessão e na área intermediária entre o subjetivo e o que é objetivamente percebido". ${ }^{4} \mathrm{O}$ espaço transicional ou transicionalidade é essa zona de intercâmbio entre o mundo interno e externo ao sujeito; quer dizer, um espaço fronteiriço onde não há limites rígidos entre fantasia e realidade. Tal espaço constitui-se, portanto, num paradoxo que jamais será inteiramente solucionado pelo indivíduo, embora este, com o passar do tempo, seja capaz de diferenciar-se dos objetos do mundo. Sempre haverá, pois, um campo de experiência compartilhada, em que se criam as condições para a brincadeira, a cultura, o jogo e a vivência dividida com o outro. Por conta disso, quando o objeto transicional perde o significado para o indivíduo, podemos supor que há aí um estado de diferenciação entre o eu e o não-eu, isto é, um estágio de desenvolvimento em que o bebê se torna uma unidade, ou que, então, torna-se "[...] capaz de sentir o self (e, portanto, os outros) como um inteiro, uma coisa com membrana limitadora e dotado de um interior e um exterior", ; perfazendo-se, assim, a totalidade do desenvolvimento "[...] que conduz até o sentimento de ser um",

Essa conquista por parte do bebê na intenção de poder sentir-se como um ser integrado e inteiro, ou um EU SOU, é, na linguagem de Winnicott, mediada pela figura materna, que, no início, será capaz de

2 Cf. DORS, L. K. Merleau-Ponty e Winnicott: intersubjetividade e psicanálise infantil. Toledo, PR: UNIOESTE/Programa de Pós-Graduação em Filosofia, 2015 [Dissertação de Mestrado]

${ }^{3}$ WINNICOTT, D. W. O brincar e a realidade. Trad. J. O. A. Abreu et al. Rio de Janeiro: Imago, 1975. P. 10

${ }^{4}$ WINNICOTT, D. W. O brincar e a realidade. Trad. J. O. A. Abreu et al. Rio de Janeiro: Imago, 1975. P. 15

${ }^{5}$ WINNICOTT, D. W. Natureza humana. Trad. D. L. Bogomoletz. Rio de Janeiro: Imago, 1990. P. 87

${ }^{6}$ WINNICOTT, D. W. Natureza humana. Trad. D. L. Bogomoletz. Rio de Janeiro: Imago, 1990. P. 87

\begin{tabular}{|c|c|l|l|l|l|}
\hline intuitio & $\begin{array}{c}\text { ISSN } \\
1983-4012\end{array}$ & Porto Alegre & Vol.9- $\mathrm{N}^{\circ} .1$ & $\begin{array}{l}\text { Julho } \\
2016\end{array}$ & p.82-97 \\
\hline
\end{tabular}


identificar e satisfazer as necessidades da criança, para, com o passar do tempo, gradativamente, frustrar tais necessidades de modo que a criança perceba que há um "outro" ali, responsável por apresentar-lhe o mundo. Mesmo depois de efetivado o processo de diferenciação do eu no indivíduo, o espaço transicional permanece como uma zona de descanso, sendo por meio dele possibilitada à criança pequena a experiência da brincadeira de forma que posteriormente lhe permitirá a partilha de experiência com outros indivíduos, como a experiência cultural e artística.

É possível observar, através dessa caracterização da transicionalidade, a proximidade com o pensamento de Merleau-Ponty, em especial, quando este reconhece, no contexto de uma "ontologia da carne", o princípio de um elo ou quiasma entre o mundo concreto e o imaginário subjetivo. Essa compreensão está, pois, ligada à ideia do homem como sujeito encarnado ao mundo, produto e produtor de sua própria experiência. $\mathrm{O}$ que ocorre, a bem da verdade, é que, embora tenha proposto uma nova abordagem como contraponto à concepção clássica de consciência (hegemonicamente cartesiana), o pensador francês parece abrir caminho a uma ontologia que, em sentido radical, desconstrói a própria noção de consciência. Essa desconstrução já se anuncia, desde as suas primeiras obras, A Estrutura do Comportamento e A Fenomenologia da Percepção, de modo que, progressivamente, ganha força a tese de que o homem é um ser consagrado ao mundo, ou seja, que mantém, com o mundo e com outrem, relações carnais. Ou ainda que, para o ser humano, "o mundo é o verdadeiro transcendental"7 , o âmbito próprio desde onde a relação com outrem, originariamente, se institui. Tal será, ainda, de maneira mais radical, o alcance máximo que se pode medir de seus trabalhos tardios, como $O$ Visível e o Invisível.

É a partir dessa premissa fenomenológico-ontológica que a obra psicanalítica de Winnicott ganha especial interesse. Noutras palavras, o psicanalista também parece oferecer elementos teóricos capitais que vão ao encontro desse debate merleau-pontyano decisivo prefigurado sob o ponto de vista de uma ontologia da "carne". Ao propor que a formação da consciência expressa uma conquista que se desenvolve a partir da existência de um ente no tempo e no espaço, bem como na relação com outro humano, o pediatra inglês toma uma posição, de fato, consonante com o pensamento de Merleau-Ponty. Winnicott explora grande parte das discussões acerca do corpo, da linguagem e da intersubjetividade.

Entende-se, ainda, que a obra winnicottiana é dotada de originalidade, em grande parte por compreender que algo importante acontece bem antes de o bebê ingressar na dinâmica das relações objetais. Ou seja, nas fases iniciais da vida, os elementos sensoriais e motores vão adquirindo, de maneira progressiva, contornos existenciais produzidos graças à adaptação bem-sucedida da figura materna às necessidades do bebê. Somente após esse percurso é que podemos formular, com propriedade, acerca da existência de um self, de uma consciência, ou de um indivíduo que se compreende na condição de um ser real, capaz de ter experiências e de relacionar-se com o mundo real.

\footnotetext{
${ }^{7}$ MERLEAU-PONTY, M. Phénoménologie de la perception. Paris: Gallimard, 1945. P. 418
}

\begin{tabular}{|c|c|c|c|c|c|}
\hline intuitio & $\begin{array}{c}\text { ISSN } \\
1983-4012\end{array}$ & Porto Alegre & Vol.9- $\mathrm{N}^{\circ} .1$ & $\begin{array}{l}\text { Julho } \\
2016\end{array}$ & p.82-97 \\
\hline
\end{tabular}


A função materna, quando "suficientemente boa", parece atuar como fundo afetivo sobre o qual emerge um indivíduo capaz de perceber e de interagir intimamente com o mundo e com o outro, de maneira a modificar e ser modificado por essa relação. Nesse particular contexto, o cuidador exerce o papel de "ego auxiliar" ao ego do bebê, auxiliando-o, principalmente, a produzir significados tanto para os objetos de seu mundo externo quanto para suas próprias sensações e percepções internas. Aos olhos de Winnicott, as sensações produzidas ao bebê através do contato com o corpo materno, além de uma percepção puramente corporal, produzem um importante equivalente psíquico. Com isso, o bebê que é segurado de uma maneira adequada tem a sensação de que, não somente seu corpo, mas também sua estrutura psíquica encontra-se integrada e protegida. É o que o psicanalista denomina de holding materno.

Ainda sobre o ato de segurar, Winnicott discorre sobre a sensibilidade dos bebês ao serem segurados, e os mecanismos que os levam a sentirem-se confortáveis e seguros no colo de algumas pessoas e, vice-versa, quando choram com outras. Dessa forma, a experiência revela que o bebê percebe, não por um mero processo intelectualizante, mas por meio de sensações ainda primitivas como o sentimento de medo, raiva, insegurança, em face àquele que o carrega em seu colo. Em função disso, por exemplo, "[...] o medo, que pode se manifestar no pesadelo sob a forma do ferimento do bebê, faz com que, na prática, a irmã maior o segure com força excessiva" ${ }^{"}$.

Do mesmo modo, a mãe dedicada comum, quando não estiver ansiosa, não aperta o filho ao segurá-lo; menos, ainda, teme deixá-lo cair. Ao adaptar a pressão de seus braços às necessidades do bebê, movendo-se lentamente e emitindo, talvez, algum som, a mãe faz com que o bebê sinta a sua respiração, o seu hálito e o calor de sua pele, proporcionando-lhe a sensação agradável de estar em seu colo. O que ocorre ainda é que, enquanto é segurado, ao sentir as partes de seu corpo integradas ou unidas com firmeza, a criança experimenta uma sensação produzida por um efeito psíquico correspondente, que lhe crie a sensação de que também seu rústico psiquismo se encontra integrado. Para citarmos as palavras do psicanalista, transcreve-se: “A integração também é estimulada pelo cuidado ambiental. Em psicologia, é preciso dizer que o bebê se desmancha em pedaços a não ser que alguém o mantenha inteiro. Nestes estágios, o cuidado físico é um cuidado psicológico"”.

É o conjunto dessas sensações prazerosas que começam lentamente a integrar a vida subjetiva do bebê, transmitindo-lhe a sensação de que o mundo lhe desponta como um ambiente saudável e seguro de se viver. Ao postular a ausência inicial de uma consciência, em seu sentido mais amplo, bem como a dependência absoluta do ego materno enquanto "ego auxiliar", o pediatra inglês se propõe examinar que, inicialmente, o corpo possui uma função peculiar, uma vez que é por intermédio do contato corporal entre o bebê e os objetos do mundo que o mesmo passa a ganhar significado e status subjetivo.

\footnotetext{
${ }^{8}$ WINNICOTT, D. W. Os bebês e suas mães. Trad. J. L. Camargo. 3. ed. São Paulo: Martins Fontes, 2006. P. 15.

${ }^{9}$ WINNICOTT, D. W. Natureza humana. Trad. D. L. Bogomoletz. Rio de Janeiro: Imago, 1990. P. 137
}

\begin{tabular}{|c|c|l|l|l|l|}
\hline intuitio & ISSN & Porto Alegre & Vol.9- $\mathrm{N}^{\circ} .1$ & $\begin{array}{l}\text { Julho } \\
2016\end{array}$ & p.82-97 \\
\hline
\end{tabular}




\section{III}

Neste ponto de nossa apresentação já é possível observar que a manifestação da consciência - conforme a acepção enunciada por Winnicott - é um fenômeno processual que se irá constituindo através do tempo e do espaço, amparado pela presença afetiva de outrem. Tomar a consciência infantil como um fenômeno em processo guarda, desde já, fortes alianças com a noção merleau-pontyana de "consciência perceptiva" na medida em que não há como compreender uma subjetividade desenraizada, isto é, separada de sua comunhão com o corpo. Numa perspectiva merleau-pontyana, a consciência e o corpo habitam-se mutuamente. Noutras palavras, há uma relação dialética entre ambos. No contexto de uma ontologia da carne, o princípio de um elo ou quiasma entre o mundo concreto e o imaginário subjetivo vai ao encontro da compreensão winnicottiana acerca daquela unidade fundamental entre a mãe e a criança. Com esse registro, Winnicott coloca em pauta a discussão sobre o tema do corpo que, à maneira de Merleau-Ponty, não se compreende via pressupostos mecanicistas, uma vez que o fenômeno da corporeidade é fonte de significação do mundo. O corpo se desvela como que investido de sentidos. É o que, primeiramente, Merleau-Ponty descreve quando estabelece uma diferenciação entre o corpo-objeto, no sentido absolutamente científico ou empírico, comparável aos objetos concretos do mundo, e o corpo-sujeito ou corpo-fenomenal, que desconstrói e transfigura outro sentido da subjetividade. Merleau-Ponty fala em termos de uma unidade psicofísica, onde há um movimento dialético entre o fisiológico e o psicológico. Assim, ao abordar o corpo como um sistema de significações interligadas a uma vida psíquica, Merleau-Ponty passa a desconstruí-lo a título de uma estrutura mecanicista, ou "um objeto para um 'eu penso",10. Em tal contexto,

O que reúne as "sensações táteis" de minha mão e as liga às percepções visuais da mesma mão, assim como às percepções dos outros segmentos do corpo, é certo estilo dos gestos de minha mão, que implica certo estilo dos movimentos de meus dedos e contribui, por outro lado, para certa configuração de meu corpo. Não é ao objeto físico que o corpo pode ser comparado, mas antes à obra de arte. ${ }^{11}$

É interessante apontar, sob esse propósito, que a comparação que o filósofo tece acerca do corpo como obra de arte advém de sua interrogação acerca da pintura. Aos olhos de Merleau-Ponty, também a pintura moderna, datada do final do século XIX e da primeira metade do século XX, traz à tona o sentido da experiência carnal. Quer dizer: tal experiência pictórica é aquela que foge da estrutura basicamente

\footnotetext{
${ }^{10}$ MERLEAU-PONTY, M. Phénoménologie de la perception. Paris: Gallimard, 1945. P. 212.

${ }^{11}$ MERLEAU-PONTY, M. Phénoménologie de la perception. Paris: Gallimard, 1945. P. 208
}

\begin{tabular}{|c|c|c|c|c|c|}
\hline intuitio & $\begin{array}{c}\text { ISSN } \\
1983-4012\end{array}$ & Porto Alegre & Vol.9- $\mathrm{N}^{\circ} .1$ & $\begin{array}{l}\text { Julho } \\
2016\end{array}$ & p.82-97 \\
\hline
\end{tabular}


"realista" da pintura clássica, que buscava reverenciar o colorido e a perspectiva dos objetos reais. Ora, na contramão da pintura clássica, Merleau-Ponty vê, na nova arte moderna, um retorno à verdadeira percepção. Isto é: embora não deixando de reproduzir nas telas o mundo tal como percebido objetivamente pelos indivíduos, o pintor investe em sua obra aspectos de sua própria personalidade, de cores e de perspectivas próprias tais como percebidas em sua experiência com o mundo. Dessa forma, a obra revela o contato do homem com o mundo; mundo esse primordialmente vivido e sentido antes de ser pensado.

No texto intitulado A linguagem indireta e as vozes do silêncio, o filósofo apresenta uma belíssima descrição acerca da observação em câmera lenta das filmagens do trabalho de Matisse:

Esse mesmo pincel que, visto a olho nu, saltava de um ato para outro, podia-se vê-lo meditar, num tempo dilatado e solene, numa iminência de começo do mundo, tentar dez movimentos possíveis, dançar diante da tela, roçá-la várias vezes, e por fim abater-se como um raio sobre o único traçado necessário. ${ }^{12}$

Não foi preciso, pois, que Matisse operasse nenhum cálculo acerca do melhor ângulo a se pintar. $\mathrm{O}$ traçado de Matisse não toma apoio em nenhuma escolha racional. O movimento de seu corpo, de suas mãos, naquele momento, era parte de sua obra e puderam captar o melhor traçado para exprimir o sentimento de Matisse. É sob esse prisma que também podemos reconhecer, de pleno direito, uma comunicação entre os sentidos, ou seja, a visão que nos remete ao tato, aos odores e à audição como também o cheiro que nos remete às imagens visuais; as cores vibrantes ou sem vida, quentes ou frias que animam nossa percepção do mundo.

Cabe, contudo, mostrar que, numa perspectiva winnicottiana, é interessante observarmos que o bebê, em seu contato inicial com o mundo, não diferencia entre o "si mesmo" e o "outro". Dessa maneira, não lhe cabe diferenciar sequer a relação de seus órgãos do sentido com os estímulos que lhe vêm do exterior. A questão é que o bebê não possui a noção intelectualizada segundo a qual os olhos seriam órgãos que corresponderiam, de maneira absoluta e arbitrária, à visão tão somente. O mesmo se passaria com os demais sentidos. Isso significa que o bebê não vê apenas com os olhos, mas com o tato, com a audição, etc. Há uma troca de funções entre as sensações. Fato é que isso é uma das descobertas capitais da Gestalttheorie, no início do século passado, ou seja, a posição, como bem diz Merleau-Ponty, de que a divisão clássica entre os sentidos é arbitrária e, por isso mesmo, superficial, grosseira. ${ }^{13} \mathrm{O}$ que a Psicologia da Forma postula é a ideia de que a nossa percepção se efetiva numa visão de conjunto e, portanto, mais integral.

\footnotetext{
${ }^{12}$ MERLEAU-PONTY, M. Signes. Paris: Gallimard, 1960. P. 48

${ }^{13}$ Cf. MERLEAU-PONTY, M. Phénoménologie de la perception. Paris: Gallimard, 1945, p. 262. E, MERLEAUPONTY, M. Le visible et l'invisible. Paris: Gallimard, 1964, p. 176.
}

\begin{tabular}{|c|c|c|c|c|c|}
\hline intuitio & $\begin{array}{c}\text { ISSN } \\
1983-4012\end{array}$ & Porto Alegre & Vol.9- $\mathrm{N}^{\circ} .1$ & $\begin{array}{l}\text { Julho } \\
2016\end{array}$ & p.82-97 \\
\hline
\end{tabular}


Nessa direção, vale aqui mencionar os estudos de Kurt Goldstein, eminente psiquiatra e neurologista alemão cujos trabalhos se embasam nos pressupostos da Gestalttheorie e que têm sido uma fonte recorrente na obra de Merleau-Ponty. Em um interessante artigo denominado $O$ Sorriso da Criança e o Problema da Compreensão de Outrem, Goldstein debate acerca de um tema que começa a despertar a atenção especial entre os psicólogos: o primeiro sorriso da criança ${ }^{14}$. O autor advoga que esse "primeiro sorriso" é a expressão de uma relação adaptada entre o organismo infantil e o mundo; mundo esse particularmente simbolizado pelo rosto materno. Há que se observar aí que, de início, o sorriso não se explica em função de um critério puramente causal, como se tratasse de um efeito estimulado pelo rosto da mãe, mas, sim, hermeneuticamente, como expressão de uma conexão para com ela, manifestada por meio do cuidado.

A expressão que se produz no movimento do sorriso consiste, significativamente, numa sensação de bem-estar, sensação que a criança experimenta em todas as condições de adaptação de seu organismo com o meio, como nos momentos de alimentação, de saciedade, de ajustes de temperatura, etc. A esse respeito, cumpre destacar que também na concepção de Goldstein a separação entre o "eu" e o "não-eu" inexiste na percepção infantil dos primeiros meses de vida. É, pois, a partir do sexto mês que o sorriso passa a figurar contornos expressivos, deixando de ser compreendido apenas como uma relação de adaptação da criança com o meio. Nesse estágio, o sorriso da criança começa a adquirir as características do sorriso do adulto, por intermédio do encontro que estabelece com outra pessoa, apresentando, por assim dizer, um tom mais elaborado.

Podemos novamente observar, a essa altura, uma considerável proximidade com a obra de Winnicott, já que o psiquiatra alemão postula que, no primeiro estágio da vida, a criança vive em uma unidade somática com a mãe, sendo que a adaptação entre o organismo infantil e o mundo é propiciada pela presença da figura materna. É sob este ângulo de tratamento que a posição de Goldstein parece convergir com a teoria winnicottiana:

O nascimento modifica, essencialmente, a situação da criança. A unidade básica entre mãe e filho é rompida. Ocorre, logo em seguida, um comportamento desordenado ou catastrófico, provavelmente relacionados com sentimentos de tensão e ansiedade. Em grande medida, brevemente a criança normal retorna num estado ordenado; ela dorme a maior parte do tempo e, uma vez acordada, não parece estar tão perturbada. Desde o aparecimento precoce do sorriso, podemos supor que uma nova adaptação está se elaborando. Por um lado, este é o efeito de novas relações corporais entre a mãe e a criança que se desenvolvem, especificamente, a partir das expressões de amor por parte

\footnotetext{
${ }^{14}$ Cf. GOLDSTEIN, K. "The smiling of the infant and the problem of understanding the 'other"'. In: The Journal of Psychology: Interdisciplinary and Applied, 1957, 44, p. 175-191 e reeditado em Selected Papers/Ausgewählte Schriften. The Hague: Martinus Nijhoff, 1971, p. 466-484. Assim como SILVA, C. A. F. "O primeiro sorriso da criança e outrem: prismas goldsteinianos". In: SILVA, C. A. F. (Org.). Kurt Goldstein: psiquiatria e fenomenologia. Cascavel, PR: Edunioeste, 2015, p. 143-162.
}

\begin{tabular}{|c|c|l|l|l|l|}
\hline intuitio & $\begin{array}{c}\text { ISSN } \\
1983-4012\end{array}$ & Porto Alegre & Vol.9- $\mathrm{N}^{\mathrm{o}} .1$ & $\begin{array}{l}\text { Julho } \\
2016\end{array}$ & p.82-97 \\
\hline
\end{tabular}


da mãe. ${ }^{15}$.

Na linguagem de Winnicott, cabe notar que ocorre uma adaptação da "mãe suficientemente boa" às necessidades do bebê, propiciando o ambiente facilitador onde a adaptação entre o organismo e o meio se realiza. Goldstein ${ }^{16}$ elabora a tese de que "[...] não há dúvida, contudo, de que, neste período, as experiências não representam um 'mundo' em torno da criança, de forma que nem um 'ego' nem um 'mundo externo' existem”. Vê-se, então, em que medida Goldstein considera a existência de um fundo intersubjetivo do qual o ego emerge, bem como a importância deste no que diz respeito ao desenvolvimento do indivíduo no mundo. Essa ideia toma corpo quando o autor discorre acerca do segundo estágio, onde "[...] a característica mais importante é o desenvolvimento de um ego bem como uma palavra objetiva separada do ego - cuja unidade jamais se perde. Ela é mantida como uma esfera particular na totalidade do ser humano"17. É assim que o autor pode reconhecer que o homem vive sempre em duas esferas de experiência, e que estas se relacionam umas com as outras sob a forma de figura e fundo. Nesse cenário, o que emerge como figura irá depender do significado particular de uma determinada experiência em relação ao processo de desenvolvimento do indivíduo.

Aqui, mais uma vez, é possível sustentar a analogia com a concepção merleau-pontyana de "carne"; concepção na qual há sempre estrutura pré-objetiva que sela um vínculo indissolúvel com o mundo. A interação figura-fundo que se manifesta está profundamente relacionada com as vivências iniciais, domínio no qual a criança e mãe constituem parte de uma mesma e única experiência. Diz-nos Goldstein:

Observamos que, na primeira fase do desenvolvimento da criança, o sentimento de bemestar não é vivido como que estando relacionado à criança sozinha, mas, sim, com alguém a quem temos vivido anteriormente num mundo onde o mesmo evento produz, em ambos, reações iguais e adaptadas, e onde o sentimento correspondente a essa adaptação tem crescido desde a experiência de auto-realização, da "existência". A partir das experiências relacionadas simultaneamente com os mesmos eventos externos se originam o sentimento de adequação mútua, o sentimento de pertencimento a outrem, de unidade - algo semelhante às experiências infantis na primeira fase ${ }^{18}$.

${ }^{15}$ GOLDSTEIN, K. "The smiling of the infant and the problem of understanding the 'other"'. In: The Journal of Psychology: Interdisciplinary and Applied, 1957, 44, p. 175-191 e reeditado em Selected Papers/Ausgewählte Schriften. The Hague: Martinus Nijhoff, 1971, p. 466-484. P. 10-11.

${ }^{16}$ GOLDSTEIN, K. "The smiling of the infant and the problem of understanding the 'other"'. In: The Journal of Psychology: Interdisciplinary and Applied, 1957, 44, p. 175-191 e reeditado em Selected Papers/Ausgewählte Schriften. The Hague: Martinus Nijhoff, 1971, p. 466-484. P. 11.

${ }^{17}$ GOLDSTEIN, K. "The smiling of the infant and the problem of understanding the 'other"'. In: The Journal of Psychology: Interdisciplinary and Applied, 1957, 44, p. 175-191 e reeditado em Selected Papers/Ausgewählte Schriften. The Hague: Martinus Nijhoff, 1971, p. 466-484. P. 12.

${ }^{18}$ GOLDSTEIN, K. "The smiling of the infant and the problem of understanding the 'other"'. In: The Journal of Psychology: Interdisciplinary and Applied, 1957, 44, p. 175-191 e reeditado em Selected Papers/Ausgewählte Schriften. The Hague: Martinus Nijhoff, 1971, p. 466-484. P. 17.

\begin{tabular}{|c|c|l|l|l|l|}
\hline intuitio & $\begin{array}{c}\text { ISSN } \\
1983-4012\end{array}$ & Porto Alegre & Vol.9- $\mathrm{N}^{\mathrm{o}} .1$ & $\begin{array}{l}\text { Julho } \\
2016\end{array}$ & p.82-97 \\
\hline
\end{tabular}


Isso significa que, a partir dessa primeira relação de união entre mãe e bebê é que os sentimentos poderão ser compartilhados, de maneira que a experiência de outrem se compreende por mim, como diria Scheler, de forma "simpática". Ora, embora eu não seja, obviamente, outrem, tenho, no entanto, condições de interagir com sua perspectiva, compartilhando, pois, suas sensações. É assim que também MerleauPonty descreve a intencionalidade manifesta nos gestos; intencionalidade tal perpassada intersubjetivamente, graças a um movimento intercorporal, radicalmente carnal. Descreve, ele:

Obtém-se a comunicação ou a compreensão dos gestos pela reciprocidade entre minhas intenções e os gestos do outro, entre meus gestos e intenções legíveis na conduta do outro. Tudo se passa como se a intenção do outro habitasse meu corpo ou como se minhas intenções habitassem o seu. O gesto que testemunho desenha em pontilhado um objeto intencional. Esse objeto torna-se atual e é plenamente compreendido quando os poderes de meu corpo se ajustam a ele e o recobrem. O gesto está diante de mim como uma questão, ele me indica certos pontos sensíveis do mundo, convida-me a encontrá-lo ali. ${ }^{19}$.

É essa ideia que Goldstein descreve a propósito da experiência do sorriso na segunda etapa do desenvolvimento infantil, quando há uma passagem mais acentuada da relação de unidade entre a mãe e o bebê ao surgimento do ego. $\mathrm{O}$ sorriso agora adquire um caráter mais relacional, de sorte que a criança passa a tornar-se capaz de sentir a experiência de outrem, ou seja, de vivenciar-se em duas esferas. Conforme Goldstein:

Esta é a estrutura do sorriso recíproco de amigos no encontro. Esta experiência de um mesmo mundo adaptado é o pressuposto da compreensão de um outro, de todo o nosso conhecimento do que está ocorrendo em "outrem". Este é o fundamento da compreensão da linguagem. É a base de toda amizade, de todo amor, onde, com surpresa e espanto, nós reconhecemos que o que está ocorrendo no "outro" é idêntico ao que está acontecendo em nós. ${ }^{20}$.

Merleau-Ponty retoma esse mesmo princípio ao se referir à percepção infantil do corpo e da intencionalidade de outrem, remetendo-se assim à percepção do próprio corpo. É o que ocorre no comportamento do bebê no exato momento em que ele abre a boca se, por brincadeira, ponho um de seus dedos entre meus dentes fazendo menção de mordê-lo.

Ora, todavia, ele quase não olhou seu rosto em um espelho, seus dentes não se parecem com os meus. Isso ocorre porque sua própria boca e seus dentes, tais como ele os sente do interior, são para ele imediatamente aparelhos para morder, e porque minha mandíbula, tal como ele a vê do exterior, é para ele imediatamente capaz das mesmas intenções. A "mordida" tem para ele imediatamente uma significação intersubjetiva. Ele percebe suas intenções em seu corpo, com o seu corpo percebe o meu e, através disso,

\footnotetext{
${ }^{19}$ MERLEAU-PONTY, M. Phénoménologie de la perception. Paris: Gallimard, 1945. P. 251-252.

${ }^{20}$ GOLDSTEIN, K. "The smiling of the infant and the problem of understanding the 'other"'. In: The Journal of Psychology: Interdisciplinary and Applied, 1957, 44, p. 175-191 e reeditado em Selected Papers/Ausgewählte Schriften. The Hague: Martinus Nijhoff, 1971, p. 466-484. P. 18.
}

\begin{tabular}{|c|c|c|c|c|c|}
\hline intuitio & $\begin{array}{c}\text { ISSN } \\
1983-4012\end{array}$ & Porto Alegre & Vol.9- $\mathrm{N}^{\circ} .1$ & $\begin{array}{l}\text { Julho } \\
2016\end{array}$ & p.82-97 \\
\hline
\end{tabular}


percebe em seu corpo as minhas intenções. ${ }^{21}$ (MERLEAU-PONTY, 1945, p. 471-472).

É o que ainda se revela na experiência do sorriso quando a criança se torna capaz de perceber, na face da mãe, uma intenção emocional. Nesse instante, não é a mãe que apenas ali sorri e espera pelo encontro, mas também a criança que pode, enfim, sentir, de seu interior, a possibilidade de voltar a unir-se com o objeto amoroso, esboçando, enfim, em sua face, a mesma intenção emocional que outrora havia apreendido no sorriso materno.

A esse respeito, Winnicott descreve a importância da comunicação materna com o bebê por meio do olhar. Em sua análise clínica, ao vislumbrar o rosto da mãe, nos casos em que tudo parece transcorrer bem, o bebê realiza um encontro consigo mesmo; ou seja, o olhar materno exerce, nesse tête-à-tête, o papel de um espelho para o bebê e é a si mesmo que o recém-nascido encontra no semblante da mãe ao olhá-lo. Nas palavras do psicanalista, tudo se passa como se o bebê pensasse: "Quando olho, sou visto; logo, existo." 22 . Tal olhar materno é o que gera no bebê a sensação plena e verdadeira do sentido de sua existência.

Quando a mãe está verdadeiramente ligada aos cuidados da criança, consegue desenvolver com ela uma relação tal que ela mesma se veja nela ou, para dizer de outro modo, sua intencionalidade é captada através do olhar do bebê, seu sorriso, seus gestos, sua face afetuosa, propiciando-lhe um sentimento verdadeiro de estar protegido e, portanto, mais seguro existencialmente. É nesse plano que a "figurabilidade do afeto" 23 primordial parece encontrar, na experiência materna, uma referência fenomenológica essencial.

É ainda analisando essa reciprocidade intencional entre os gestos da mãe e do bebê que MerleauPonty sempre mais toma distância de Piaget, no âmbito da psicologia infantil. O ponto crucial é a tese relativa ao egocentrismo infantil e à divisão do desenvolvimento do pensamento em fases delimitadas. Merleau-Ponty situa a posição teórica do epistemólogo suíço como um pensamento solidamente calcado em pressupostos cartesianos. O que o filósofo então propõe é que, se quisermos fundamentalmente compreender o universo infantil, é preciso efetuar um "alargamento da razão", renunciando, pois, o ponto de vista exclusivo de adulto, tal qual a mãe suficientemente boa, como diria Winnicott, o faz ao intuitivamente compreender e satisfazer as necessidades de seu bebê. Se quisermos retornar à verdadeira percepção das coisas é necessário que não sacrifiquemos, ao estilo metódico de Piaget, o olhar infantil subjugando-o ao modelo de pensar do próprio adulto, modelo esse, cartesiano, que se tornou hegemônico na ciência e na filosofia clássicas. Dessa forma, não é possível que a criança adote a atitude do

\footnotetext{
${ }^{21}$ MERLEAU-PONTY, M. Phénoménologie de la perception. Paris: Gallimard, 1945. P. 471-472.

${ }^{22}$ WINNICOTT, D. W. O brincar e a realidade. Trad. J. O. A. Abreu et al. Rio de Janeiro: Imago, 1975. P. 157.

${ }^{23}$ Cf. AYOUCH, T. Maurice Merleau-Ponty et la psychanalyse: la consonance imparfaite. Paris: Le Bord de L'Eau, 2012.
}

\begin{tabular}{|c|c|l|l|l|l|}
\hline intuitio & $\begin{array}{c}\text { ISSN } \\
1983-4012\end{array}$ & Porto Alegre & Vol.9- $\mathrm{N}^{\mathrm{o}} .1$ & $\begin{array}{l}\text { Julho } \\
2016\end{array}$ & p.82-97 \\
\hline
\end{tabular}


egocentrismo, já que ela não se encontra nem voltada a si mesma e nem, tampouco, ao mundo externo. A diferenciação entre "externo" e "interno" só está presente na consciência do adulto. Noutras palavras, a criança não possui ainda a ciência de um "si-mesmo", isto é, não se põe segundo a ótica de uma "subjetividade privada" como referência de suas percepções. A questão é que a verdade objetiva que minha consciência de adulto produz é tão somente uma das mais diversas maneiras que meu ser é capaz de interpretar. A objetividade é, por assim dizer, apenas uma perspectiva que, ao revelar a diferenciação entre o "eu" e as coisas, trata de esconder o seu inverso, como a unidade intersubjetiva de minha consciência com o mundo.

Em face disso - esboçando um princípio de "solução" -, escreve Merleau-Ponty, numa nota de $O$ Visível e o Invisível, trata-se de "[...] re-aprender a criança, o alter ego, o irrefletido em mim por uma participação lateral, pré-analítica, que é a percepção" ${ }^{24}$. É, antes de tudo, em unidade com o mundo perceptivo que a consciência infantil põe em xeque todo postulado solipsista. Ela está aberta ao mundo e é, via essa abertura, que ela se associa a diferentes perspectivas, não havendo, pois, diferenciação entre "eu" e "outrem". Eis a tese capital: "[...] o conhecimento do outro ilumina o conhecimento de si",25, de modo que a questão do "outro" nada mais reflete do que o próprio "espelho do problema do eu"26; problema esse, como se sabe, "culturalmente ocidental" 27.

\section{IV}

Ora, é na contramão desse páthos ocidental que Winnicott também se encaminha. Em $O$ Brincar e a Realidade, o pediatra e psicanalista refere-se ao espaço transicional como uma área de relações inexplorada pelos estudos psicológicos:

Essa área de desenvolvimento [o espaço transicional] e experiência individuais parece ter sido desprezada, enquanto a atenção se focalizava na realidade psíquica, pessoal e interna, e sua relação com a realidade externa ou compartilhada. A experiência cultural não encontrou seu verdadeiro lugar na teoria utilizada pelos analistas em seu trabalho e em seu pensar. ${ }^{28}$.

Winnicott aponta para a importância de saber que, mesmo ainda na vida adulta, o indivíduo possa transitar por essa zona intercambiável entre o real e a fantasia, que se efetiva, ao fim e a cabo, como um espaço de descanso, um espaço de criação que se perfaz através das artes, da filosofia e da cultura em

\footnotetext{
${ }^{24}$ MERLEAU-PONTY, M. Le visible et l'invisible. Paris: Gallimard, 1964. P. 257

${ }^{25}$ MERLEAU-PONTY, M. Phénoménologie de la perception. Paris: Gallimard, 1945.p. 215.

${ }^{26}$ MERLEAU-PONTY, M. Psychologie et pédagogie de l'enfant: Cours de Sorbonne (1949-1952). Paris: Verdier, 2001. P. 288.

${ }^{27}$ MERLEAU-PONTY, M. Le visible et l'invisible. Paris: Gallimard, 1964. P. 274.

${ }^{28}$ WINNICOTT, D. W. O brincar e a realidade. Trad. J. O. A. Abreu et al. Rio de Janeiro: Imago, 1975. P. 9
}

\begin{tabular}{|c|c|c|c|c|c|}
\hline intuitio & $\begin{array}{c}\text { ISSN } \\
1983-4012\end{array}$ & Porto Alegre & Vol.9- $\mathrm{N}^{\circ} .1$ & $\begin{array}{l}\text { Julho } \\
2016\end{array}$ & p.82-97 \\
\hline
\end{tabular}


geral. O autor, então, escreve que:

Se um adulto nos reivindicar a aceitação da objetividade de seus fenômenos subjetivos, discerniremos ou diagnosticaremos nele loucura. Se, contudo, o adulto consegue extrair prazer da área pessoal intermediária sem fazer reivindicações, podemos então reconhecer nossas próprias e correspondentes áreas intermediárias, sendo que nos apraz descobrir certo grau de sobreposição, isto é, de experiência comum entre membros de um grupo na arte, na religião, ou na filosofia. ${ }^{29}$

Tal passagem nos permite observar que também Winnicott reconhece que há significativas diferenças entre a consciência da criança e a consciência do adulto. É, contudo, necessário que este último nunca abandone por completo o elo com sua vivência infantil, uma vez que é por meio desta que o contato mais original e criativo com o mundo se torna possível.

Aos olhos de Merleau-Ponty, é justamente esse retorno à vivência infantil que Piaget recusa teoricamente ao enquadrar o pensamento infantil em categorias bem definidas, lançando, pois, mão de dicotomias como "matéria" e "forma", "exterior" e "interior". A esse modo, imbuído de certo espírito cartesiano, Piaget deixa de supor que faltam à criança essas distinções ao analisar tais respostas unicamente em relação a esse registro de distinção. Merleau-Ponty afirma que, "[...] literalmente, ele não

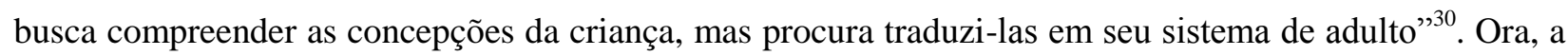
pretensão de objetividade científica está longe de ser levada a cabo, uma vez que não há efetivo distanciamento entre o observador e o observado. Quando Piaget observa o comportamento infantil, termina por fazê-lo segundo o seu próprio ponto de vista de adulto, o que escamoteia o real entendimento do mundo da criança.

As leis psicológicas não devem, portanto, ser descritas como sequência de fatos encontrados em todo e qualquer lugar. Como avalia Merleau-Ponty, a psicologia só será científica quando, de fato, for capaz de promover as condições de compreensão de diferentes caminhos, seja dos adultos, dos primitivos, seja, em particular, das crianças como sistemas paralelos que produzem respostas para o mesmo problema por meios diversos ou por lógicas paralelas. Não se trata aqui de dar razão à criança ou ao primitivo, mas, antes de tudo, “[...] de alargar nossa razão para torná-la capaz de compreender o que em nós e nos outros precede e excede a razão" ${ }^{\text {"31 }}$. Nessa medida, se quisermos compreender a manifestação da consciência infantil, é necessário que realizemos a operação proposta por Jacob L. Moreno, fundador da Escola do Psicodrama, qual seja, a de tomar distância de nosso papel costumeiro e "[...] despertar nossa própria espontaneidade" ${ }^{32}$.

\footnotetext{
${ }^{29}$ WINNICOTT, D. W. O brincar e a realidade. Trad. J. O. A. Abreu et al. Rio de Janeiro: Imago, 1975. P. 29

${ }^{30}$ MERLEAU-PONTY, M. Psychologie et pédagogie de l'enfant: Cours de Sorbonne (1949-1952). Paris: Verdier, 2001. P. 185

${ }^{31}$ MERLEAU-PONTY, M. Signes. Paris: Gallimard, 1960. P. 154

32 MERLEAU-PONTY, M. Psychologie et pédagogie de l'enfant: Cours de Sorbonne (1949-1952). Paris: Verdier, 2001. P. 475.
}

\begin{tabular}{|c|c|c|c|c|c|}
\hline intuitio & $\begin{array}{c}\text { ISSN } \\
1983-4012\end{array}$ & Porto Alegre & Vol.9- $\mathrm{N}^{\circ} .1$ & $\begin{array}{l}\text { Julho } \\
2016\end{array}$ & p.82-97 \\
\hline
\end{tabular}


Ao se referir, por exemplo, à teoria freudiana da sexualidade, atesta Merleau-Ponty ${ }^{33}$ : “A psicologia da criança não é a evolução de uma natureza oculta. Assim, para Freud, as determinações anatômicas são dadas de saída, mas são quase nada. Há determinações do modo de sexualidade em certo momento, em função das posições diferentes que a criança assume na constelação familiar".

Isso explica que, tanto sob uma perspectiva psicanalítica quanto fenomenológica, por mais que haja um processo de separação da consciência, da identificação de uma temporalidade cronológica, o indivíduo, mesmo na fase adulta, pode manter-se fixado naquelas experiências iniciais, sendo que o tempo que registra o movimento dos ponteiros de um relógio não é o mesmo que transpassa as vias da existência, definindo, em última análise, a experiência humana. Aqui, os comportamentos não são explicáveis mediante uma relação causal com o espaço, o tempo ou os fenômenos do mundo concreto. A conquista do tempo, conforme Winnicott confere o maior apreço em sua obra, encontra-se intimamente relacionada com o sentimento de ser. É o que, com propriedade, descreve Santos:

Inicialmente, as noções de tempo, espaço e realidade são pessoais - pois, no início, diz respeito às conquistas que cada um tem de fazer dessas noções que nos situam no mundo. Dessa forma, este bebê que já se encontra no mundo precisa conquistar uma noção de tempo. Digo "uma" porque essa noção ainda não é a mesma que nós, enquanto pessoas inteiras e integradas compartilhamos, só se tornando uma noção de tempo compartilhada quando o bebê conseguir lidar com os objetos do mundo externo de forma objetiva. ${ }^{34}$

A noção de temporalidade também está aqui relacionada às necessidades e aos impulsos somáticos, assim como às condições suficientemente boas de provisão ambiental e de cuidados dos quais dependerá o movimento que o infante fará em uma determinada direção. Tal interpretação do tempo infantil não deve, pois, ser considerada conforme o esquema cronológico próprio do indivíduo adulto.

Noutro texto, intitulado $O$ Bebê como Pessoa, Winnicott descreve a atividade lúdica de um bebê com uma colher junto à mãe. Após analisar os pormenores dessa relação, o autor conclui que "a melhor coisa que aprendemos na observação do bebê foi o seguinte: Vimos, pelo que aconteceu, que ele não é apenas um corpo, mas uma pessoa" ${ }^{, 35}$. Ora, isso não é pouco! O que essa experiência aviva é que o bebê desvela uma maneira própria de ser que deve ser compreendida pelo adulto. O psicanalista complementa:

As idades em que os vários gêneros de habilidades se desenvolvem são interessantes de registrar, mas havia nisso mais do que mera habilidade. Havia brincadeira. Ao brincar, o bebê mostrou que reunira algo em si próprio que poderia denominar-se o material para brincar, um mundo interior de vivacidade imaginativa, que se manifestou pela

\footnotetext{
${ }^{33}$ MERLEAU-PONTY, M. Psychologie et pédagogie de l'enfant: Cours de Sorbonne (1949-1952). Paris: Verdier, 2001. P. 475.

${ }^{34}$ SANTOS, E. S. Winnicott e Heidegger: aproximações e distanciamentos. São Paulo: DWW Editorial/FAPESP, 2010. P. 102-103.

${ }^{35}$ WINNICOTT, D. W. A criança e o seu mundo. Trad. Álvaro Cabral. Rio de Janeiro: LTC, 2008. P. 87.
}

\begin{tabular}{|c|c|c|c|c|c|}
\hline intuitio & $\begin{array}{c}\text { ISSN } \\
1983-4012\end{array}$ & Porto Alegre & Vol.9- $\mathrm{N}^{\circ} .1$ & $\begin{array}{l}\text { Julho } \\
2016\end{array}$ & p.82-97 \\
\hline
\end{tabular}


brincadeira. ${ }^{36}$.

Podemos compreender, pela leitura de mais essa passagem, que Winnicott está se referindo a uma situação mais ampla do que a mera descrição de um comportamento infantil. Trata-se de reconhecer que o bebê expressa-se autenticamente por meio da brincadeira, e não por uma habilidade pura e simples. O que torna esse gesto efetivamente original é a capacidade imaginativa que o mundo infantil perfaz. Por outro lado, essa criatividade toda exige por parte do adulto - no caso aqui, em geral, a própria mãe - um retorno recíproco, se quiser estabelecer uma experiência mais própria e original com a criança.

Ora, é essa perspectiva que Merleau-Ponty jamais perde de vista quando enuncia o princípio de um "alargamento da razão". O filósofo não deixa de reconhecer que a compreensão da criança se situa como um empreendimento difícil para o adulto, uma vez que "[...] a criança reage à nossa atitude com tal prontidão a ponto de não nos darmos conta da mudança que nossa presença de adulto produz em suas reações" ${ }^{37}$. Sob esse prisma, as diferentes concepções de criança ao longo da história ganham seus contornos estereotipando-as via um critério similar, como vimos, ao ser praticado por Piaget. Como sugere Merleau-Ponty ${ }^{38}$, a propósito da psicologia: "há sempre superestimação ou subestimação do objeto: viver uma relação de igualdade com outrem é o que há de mais raro em nossa experiência. O outro parece-nos mais forte ou mais fraco".

A nosso ver, no decorrer de sua carreira como clínico e teórico, Winnicott empreendeu esforços consideráveis ao compreender o processo de amadurecimento mediante uma perspectiva mais ampla e original daquela apresentada pelos pressupostos da psicologia mecanicista. É o que ele discute acerca da natureza humana:

Se aquilo que é bom, verdadeiro e natural nos seres humanos e na criação dos pequenos seres humanos deve ser resguardado da ação do rolo compressor da ciência, isso só pode sobrevir por meio de uma extensão da investigação científica a todos os aspectos da natureza humana. [...] Ora, todos queremos tornar possível que cada indivíduo encontre e estabeleça sua identidade de maneira tão sólida que, com o tempo, e a seu próprio modo, ele ou ela adquira a capacidade de tornar-se membro da sociedade - um membro ativo e criativo, sem perder sua espontaneidade pessoal nem desfazer-se daquele sentido de liberdade que, na boa saúde, vem de dentro do próprio indivíduo. ${ }^{39}$.

Assim é que a criança também deve ser reconhecida em sua mais real condição, acompanhada pelo adulto, para poder vir a se tornar, em seu processo de amadurecimento, um ser humano autêntico,

\footnotetext{
${ }^{36}$ WINNICOTT, D. W. A criança e o seu mundo. Trad. Álvaro Cabral. Rio de Janeiro: LTC, 2008. P. 87.

${ }^{37}$ MERLEAU-PONTY, M. Psychologie et pédagogie de l'enfant: Cours de Sorbonne (1949-1952). Paris: Verdier, 2001. P. 466.

${ }^{38}$ MERLEAU-PONTY, M. Psychologie et pédagogie de l'enfant: Cours de Sorbonne (1949-1952). Paris: Verdier, 2001. P. 467.

${ }^{39}$ WINNICOTT, D. W. A família e o desenvolvimento individual. Trad. M. B. Cipolla. São Paulo: Martins Fontes, 2013. P. 40.
}

\begin{tabular}{|c|c|c|c|c|c|}
\hline intuitio & $\begin{array}{c}\text { ISSN } \\
1983-4012\end{array}$ & Porto Alegre & Vol.9- $\mathrm{N}^{\mathrm{o} .1}$ & $\begin{array}{l}\text { Julho } \\
2016\end{array}$ & p.82-97 \\
\hline
\end{tabular}


espontâneo e capaz de relacionar-se com o mundo tão criativamente a ponto de sentir que é feita do mesmo "estofo" ou "tecido" do mundo, isto é, carnalmente unida a ele, sem, contudo, perder sua própria liberdade de tornar-se si mesma. É essa "notável convergência com uma experiência em que participamos", como diz Merleau-Ponty ${ }^{40}$, que torna a fenomenologia e a psicologia da criança discursos consonantes.

\section{Referências}

AYOUCH, T. Maurice Merleau-Ponty et la psychanalyse: la consonance imparfaite. Paris: Le Bord de L'Eau, 2012. DORS, L. K. Merleau-Ponty e Winnicott: intersubjetividade e psicanálise infantil. Toledo, PR: UNIOESTE/Programa de Pós-Graduação em Filosofia, 2015 [Dissertação de Mestrado].

GOLDSTEIN, K. "The smiling of the infant and the problem of understanding the 'other'". In: The Journal of Psychology: Interdisciplinary and Applied, 1957, 44, p. 175-191 e reeditado em Selected Papers/Ausgewählte Schriften. The Hague: Martinus Nijhoff, 1971, p. 466-484.

http://dx.doi.org/10.1007/978-94-010-2855-4_17 . "O sorriso da criança e o problema do conhecimento de outrem". Tradução de Claudinei Aparecido de Freitas da Silva. [a ser publicado]. MERLEAU-PONTY, M. Phénoménologie de la perception. Paris: Gallimard, 1945. . Signes. Paris: Gallimard, 1960. . Le visible et l'invisible. Paris: Gallimard, 1964. . Psychologie et pédagogie de l'enfant: Cours de Sorbonne (1949-1952). Paris: Verdier, 2001.

PONTALIS, J.-B. Entre o sonho e a dor. Tradução de Cláudia Berliner. Aparecida, SP: Ideias e Letras, 2005. SANTOS, E. S. Winnicott e Heidegger: aproximações e distanciamentos. São Paulo: DWW Editorial/FAPESP, 2010.

SILVA, C. A. F. "O primeiro sorriso da criança e outrem: prismas goldsteinianos". In: SILVA, C. A. F. (Org.). Kurt Goldstein: psiquiatria e fenomenologia. Cascavel, PR: Edunioeste, 2015, p. 143-162.

WINNICOTT, D. W. A criança e o seu mundo. Trad. Álvaro Cabral. Rio de Janeiro: LTC, 2008.

. A família e o desenvolvimento individual. Trad. M. B. Cipolla. São Paulo: Martins Fontes, 2013. . Natureza humana. Trad. D. L. Bogomoletz. Rio de Janeiro: Imago, 1990.

O brincar e a realidade. Trad. J. O. A. Abreu et al. Rio de Janeiro: Imago, 1975. . Os bebês e suas mães. Trad. J. L. Camargo. 3. ed. São Paulo: Martins Fontes, 2006.

Recebido em: 30/11/2015

Aprovado para a publicação em: 17/06/2016

${ }^{40}$ MERLEAU-PONTY, M. Signes. Paris: Gallimard, 1960. P. 298.

\begin{tabular}{|c|c|l|l|l|l|}
\hline intuitio & $\begin{array}{c}\text { ISSN } \\
1983-4012\end{array}$ & Porto Alegre & Vol.9- $\mathrm{N}^{\mathrm{o}} .1$ & $\begin{array}{l}\text { Julho } \\
2016\end{array}$ & p.82-97 \\
\hline
\end{tabular}

